\section{Criteria for library handbooks}

\section{Content}

- Essential information: full identification of the school and library; location (street address, room number); days and hours of service; date of handbook's publication (if frequent revision is not expected, this is often coded, as its usefulness is primarily internal).

- Services provided: circulation; interlibrary loan; reference; online searching; bibliographic instruction; regulations regarding use, including eligibility.

- Means of contacting departments: telephone numbers; names, if turnover is infrequent or revision will be easy.

- Methods of access to collections: catalogs; indexes \& abstracts; staff assistance (role of the librarian and encouragement for users to seek assistance).

\section{Useful additional information}

- Information about other related information and research sources.

- Floorplans or other simple directions to guide users to desired information.

- Table of contents or index (determined by size and complexity of handbook).

- History of the library (also special architectural features).

-Special collections or related services.

\section{Order of presentation}

- Most basic information (identification, location, etc.) must be given most prominence (cover, or at beginning).

- Constantly needed information (hours, telephone numbers, etc.) should be placed to facilitate access (beginning, end, cover, or insert).

- Bulk of descriptive information should be ar- ranged in order of decreasing importance to the user (since readers are unlikely to read the handbook from cover to cover-the earlier information is presented, the more likely the reader can absorb it).

-Information presented in a logical manner; related items grouped.

\section{Style of writing} ble.

- Narrative should be brief and concise as possi-

- Terminology should be explained from the reader's point of view; avoid technical jargon whenever possible.

- The tone should be positive and should invite interest in reading the handbook and using the library.

- Headings should be made with the reader's interest in mind and should be written to facilitate scanning. This is important when a handbook is too brief to require an index.

- An index depends on the size and complexity of the guide's contents.

\section{Format and design}

-Attractive in appearance.

-Easy to understand.

- Handy to use.

-Easy to obtain.

-Designed for retention.

- Economical to revise.

-Typeface (gives character to a page, resulting in a streamlined appearance).

- Illustrations: add to, not detract from the guide's attractiveness and usefulness; serve a purpose; placement with related passages of text; conform to limitations of the printing process; are of high quality; well produced; color (for emphasis and liveliness, ease in reading).

\title{
Information crisis in Latin America
}

In the 1970s bibliographic databases offered through such services as DIALOG and ORBIT were made available to libraries in Mexico and Latin America. Since there were very few professionals trained to take advantage of these services, librarians in these countries took it upon themselves to study the capabilities of the databases and convince others of the benefits that they offered.

At the same time, the Mexican government was increasing its efforts to accelerate the country's technological growth, and in the process discovered that information constituted the raw material for developing national programs. The number of users of bibliographic databases grew as the value of access to international information was recognized.

Libraries, universities, research centers, and other information agencies soon began to evaluate these services at professional neetings. Visits from system vendors became increasingly frequent, and have continued through the present time when almost all of them have local offices.

Unfortunately, in 1982 Mexico was hit with one of its worst economic crises involving inflation, foreign debt, manufacturing slumps, unemployment, and a series of critical peso devaluations. The situation has been gloomy ever since and the peso continues to slide in relation to the U.S. dollar while 
the country is immersed in an arduous struggle to rescue its economic stability.

The cost of bibliographic searching has soared incredibly. In April 1987 a search in DIALOG's chemistry database cost $\$ 178$ per hour. At the exchange rate of 1400 Mexican pesos per dollar, such a search would cost 249,200 pesos without considering any additional charges for national or international telecommunications networks. An institution with an annual budget of $5,000,000$ pesos for database searching can perform less than 20 hours worth of searches for the year.

Recent studies indicate that by the end of the first quarter of 1988 one dollar will be worth 2000 pesos, which will make an hour's worth of chemistry searching cost 356,000 pesos. As time goes by it is more difficult to maintain subscriptions to database services in Mexico. The problem is not, as it once was, a lack of appreciation for their capabilities-professionals in Mexico are aware of the importance of enhanced subject access and fulltext retrieval, for example-but it is an economic one.

It was a long time before we realized the fact that scientific and humanistic bibliographic information was indispensable to support the social, cultural, economic, and technological develop- ment of our country. We have been advancing, in spite of many difficulties, by creating a national database and exploring new technologies, but we are dangerously close to being isolated.

It is true that the database companies need not necessarily be concerned about our situation, because they can always recruit new clients from industrialized nations should they lose our business. But they may wish to consider whether they have an ethical or social commitment to prevent the bibliographic isolation of developing countries.

Some alternate strategies might include: reduced rates for different countries (perhaps based on GNP), special discounts for the databases in greatest demand, no rate increases over a longer amount of time, or more generous terms of payment.

The major suppliers should seriously study this situation. If not, the advances that the Latin American countries have made in information technology will be set back 20 years. It is much worse to know that you cannot have something you need, than never to realize that you need it.-José Orozco Tenorio, Head Librarian, Instituto Tecnológico Autónomo de México (ITAM), Río Hondo No.1, Col. Progreso Tizapán, Del. A. Obregón, 01000 México City, D.F., México.

\section{Eight Library/Book Fellow positions open}

Applications are now being accepted for the 1988-89 Library/Book Fellows Program, jointly sponsored by ALA and the United States Information Agency. Funding will permit the placement of U.S. citizens in approximately eight of the following twelve institutions beginning in September 1988: University of Malawi (Zomba); Makerere University-East African School of Librarianship (Kampala, Uganda); Liberian Bar Association (Monrovia); Simon Bolivar University, Graduate Program in Management of Information Services (Caracas, Venezuela); Argentina National Commission for Popular Libraries (Buenos Aires); Asian Institute of Technology (Bangkok, Thailand); National Library of the Philippines (Manila); American Library in Paris (Paris, France); Public Library of Umea and the Vasterbotten County Library (Umea, Sweden); Sanaa University Library (Sanaa, North Yemen); University of Khartoum (Khartoum, Sudan); and the Egyptian Society for the Dissemination of University Culture and Knowledge (Cairo).

Stipends for Library/Book Fellows are $\$ 23,000$ per year. Travel expenses to and from will be reimbursed and health and life insurance coverage are provided. Some hosts will assist with housing. Eligibility requirements are: U.S. citizenship; command of the language of the host country is desired; education and experience in library or information science, publishing, or other fields directly related to the interests and needs of specific projects, with demonstrated competency as required.

For more information on these positions, contact Robert P. Doyle, Director, Library/Book Fellows Program, American Library Association, $50 \mathrm{E}$. Huron St., Chicago, IL 60611; (800) 545-2433 (in Illinois, (800) 545-2444). Applications for particular positions must be received by April 15, 1988.

\section{Ethnic papers wanted}

Ethnic Forum, a journal of ethnic studies and ethnic bibliography, is calling for papers pertaining to American and Canadian ethnic bibliography and ethnic historiography, including articles on individual ethnic groups. Papers on American ethnic research institutions, archives, and libraries will also be considered. Contact Lubomyr R. Wynar, Editor, Ethnic Forum, Center for Ethnic Studies, Kent State University, Kent, OH 44242. Submission deadline is April 29, 1988. 


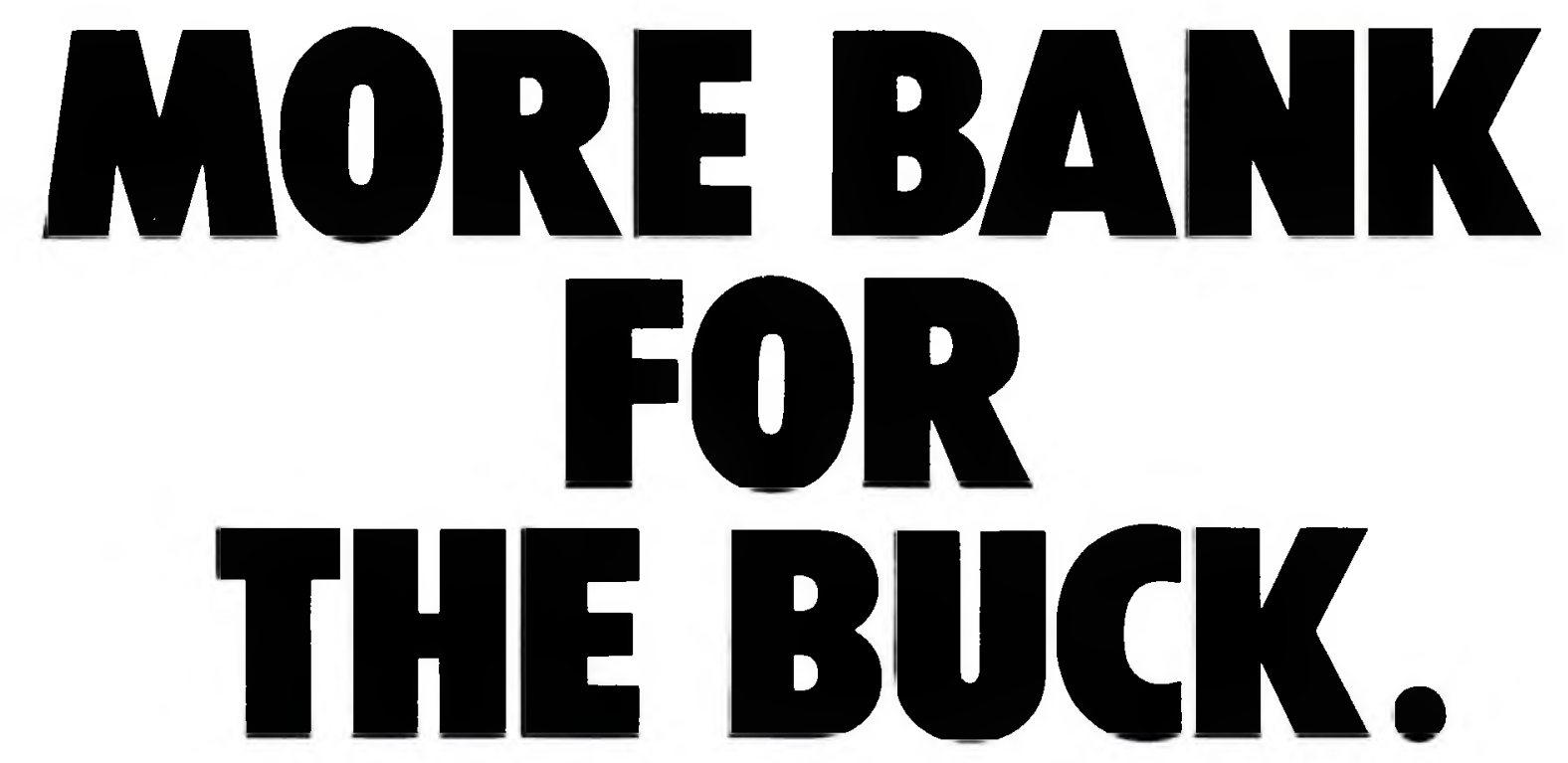

When they have questions about banks, do you have the answers?

Sheshunoff bank information is bona fide bank information. That's why over 13,000 bankers use our books and reports.

You can get the bank data you need the way you want to use it. Complete with guides to how to use it.

You can have books that quickly analyze every bank in the country. Detailed analysis on all the banks in a

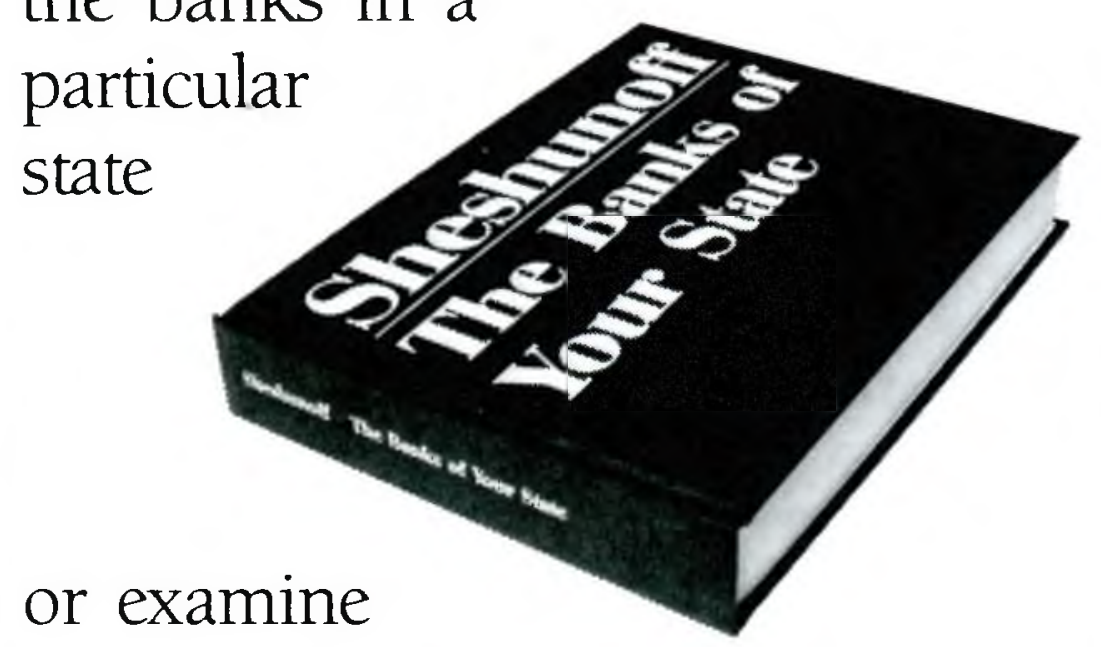
just one bank in as much detail as you want. And more.

You don't need to be a banker to use our information. Anyone who can compare numbers can find answers to their questions with our useful reference tools.

And our industry surveys present easy-tofollow data from banks across the country.

No resource is more thorough, more accurate, or easier to use.

Our Customer Service Representatives will be happy to tell you more about our books, reports, and surveys.

You can even examine a book for 30 days without obligation. For more information, please call us at (512) 472-2244.

Sheshunoff \& Company, Inc. One Texas Center 505 Barton Springs Road Austin, Texas 78704

\section{Sheshumoff \\ Alight Pertormance Banking}




\section{The Barnhart Dictionary of Etymology \\ The Core Vocabulary of Standard English -Produced by American Scholarship}

By ROBERT K. BARNHART with SOL STEINMETZ, Managing Editor 1,248pp. approx. 1988

ISBN 0-8242-0745-9 \$59 U.S. and Canada, $\$ 69$ other countries.

"Makes the fascinating game of tracing the origins of our words accessible to the nonscholar." -ROBERT MACNEIL THE MACNEIL/LEHRER NEWS HOUR Co-Author of The Story of English

\section{Barnhart}

\section{Redefines the}

Etymological Dictionary

The Barnhart Dictionary of

Etymology traces the evolution of 30,000 words basic to contemporary American English, presenting the development of our language in terms every reader can understand. Avoiding abbreviations and technical terminology, BDE entries interweave thousands of linguistic and historic facts to explain when and where a word first appeared, how it changed, and what were the sources of its formation or coinage.
A Practical Tool for Researchers at All Levels

The $B D E$ has a place in all types of libraries:

\section{- High School Libraries}

Ideal for beginning language arts or vocabulary programs, the entries of the $B D E$ clearly explain the development of meaning, spelling, pronunciation, and function in English.

- College and University Libraries

For any student of the English language, literature, or American culture, the $B D E$ consolidates information from the standard resources with new material in a single, easy-to-use volume.

\section{- Public Libraries}

The casual reader will find the $B D E$ a companion volume to the reading of the classics, history, current affairs, or popular literature.

\section{Thousands of New} Americanisms Covered

The BDE focuses on the English language as it is written and spoken in the United States today, featuring thousands of terms never before treated in an etymological dictionary.

\section{Complete}

Historical Perspective in a Single Volume

From Old and Middle English to new American coinages, the $B D E$ gives the broadest historical coverage of English etymology currently available, with specific dates pinpointing linguistic changes.

Add The Barnhart Dictionary of Etymology to your reference collection today-and introduce your patrons, students, and staff to the story of our language in action.

\section{To Place Your Order, Call Toll-Free: 1-800-367-6770}

In New York State call 1-800-462-6060; in Canada call collect 212-588-8400.

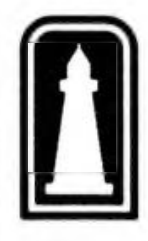

\section{THE H.W. WILSON COMPANY}

950 University Avenue Bronx, New York 10452 (212) 588-8400 